\title{
Working with Nonprofit Organizations in Community Settings: Concept, Problem Identification
}

Elizabeth B. Bolton and Anna Guest-Jelley

Nonprofits do not just happen. They are conceived by some person or persons who are usually passionate about a problem or issue that does not have a ready solution. The first step in the development of the nonprofit organization is identifying the problem or issue that needs to be addressed and refining the concept of mission.

\section{What is the problem or issue?}

Nonprofit organizations often address a social problem or an issue that remains unsolved by governmental or for-profit organizations. Examples include illiteracy, hunger, homelessness, and animal adoptions-all referred to as social problems generally because they identify the unmet needs of a sizeable part of the population that therefore affect society as a whole. There are a variety of meanings for the phrase "social problem," but the question at hand for budding nonprofits remains the same: what issue, or problem, are they going to try to address, lessen, and/or solve, and how?

Often, the more focused the organization is at its inception, the more likely it will deliver measurable impact. For example, the organization's overall goal may be to solve world hunger, but it may begin by starting a local soup kitchen or coordinating a monthly food collection drive.

\section{Who does the problem affect?}

While you are considering what problem the organization will address, it is also very important to determine just who the problem affects. This is the time to begin identifying your target audience/client. The more specific you are when you identify your proposed client group or target audience, the greater the probability that you will reach them with your organization's services or products. For example, if illiteracy is the issue or problem you seek to address, will your target audience be illiterate adults, at-risk youth with reading disabilities, non-English speaking immigrants, etc.-each group will require a different approach.

1. This publication is FCS9243, one of a series of the Department of Family, Youth and Community Sciences, Florida Cooperative Extension Service, Institute of Food and Agricultural Sciences, University of Florida. First published: June 2009. Rviewed June 2012. Please visit the EDIS Web site at http://edis.ifas.ufl.edu

2. Elizabeth B. Bolton, Ph.D., professor of Community Development, Department of Family, Youth and Community Sciences; Florida Cooperative Extension Service; Institute of Food and Agricultural Sciences; University of Florida; Gainesville, Florida 32611 - 0310; and, Anna Guest-Jelley, MFYCS, MA, director of Violence Prevention Program, Peaceful Paths Domestic Abuse Network, also of Gainesville, FL. 


\section{Economic, geographic, and ethical dimensions}

Most social problems are complex and defy simple solutions. For that reason, it is important to look at the issue from every possible perspective, starting with the economic, geographic and ethical dimensions. A nonprofit organization should consider all of these. The economic dimensions of the problem will address the financial impact of the problem on the community, the family, and/or the individual. Geographic aspects to consider include where the problem occurs, or where the target population is located. Is the target population rural and far from facilities, or urban and still hard to reach? Ethical dimensions might include the consequences of various treatments of the problem. For example, using the previous example, will the literacy program require a client to be away from home when his or her children need care? What qualifications or credentials will be required of the non-profit's staff who will deliver the intended services? These are just a few of the questions that need to be resolved when considering the development of an organization to address a specific problem.

\section{What will happen if the problem is not addressed?}

A thorough analysis of the problem will require an answer to the question of "What will happen if the problem is not addressed?" It is important to thoroughly analyze the current situation. Make projections based on research and experience about what will happen if things remain the same, i.e. if the issue is not addressed. Consider worst-case scenarios for the short- and long-term, and everything in between; then consider how these might be mitigated.

\section{Who else is addressing the problem?}

Consult other local organizations, your target audience, and anyone you can think of to see who else is addressing the problem. Find out what services/products they provide, and how what your organization plans to offer will be different. If there are areas where the service/product will overlap, consider ways to work together and to target your audience.

\section{What have the outcomes been thus far, and why?}

Gather any data that has been collected about this problem by other organizations. Determine what the outcomes have been and learn from them. You may decide to change the focus of the organization or to reexamine the problem. Conversely, your resolve to do something about the problem may be strengthened. Real-life situations are compelling in terms of motivating action.

\section{What's missing?}

Now that you have collected information from other organizations, and talked to them, you are in a position to assess their effectiveness. What is missing or needs to be done differently? What gap in services/products can your organization fill?

\section{Why the organization is needed}

With all your research in front of you, take some time for honest assessment. Write a statement, with other stakeholders in the organization, as to why the organization is needed. Having a written explanation will serve several important purposes:

- You will further clarify the organization's purpose and mission 
- Stakeholders will have a chance to discuss and debate ideas

- You will know that the organization is needed

- If the organization does not seem as necessary as you thought, then you can go back to the drawing board

If your writing session yields different results than you expected (for instance, it seems the organization lacks definition, and therefore may not be able to meet the intended need successfully, or your research has revealed resources that already fulfill purpose for a particular target audience), then you can work from there. Either way, you will work with your written product and continue to refine goals.

\section{What problem it will solve}

As discussed earlier, it is important to have two descriptions of the problem: what you want to do, and what you are going to do. The first description should speak to the larger problem at hand, the problem that which you aim to solve. As with the earlier example, the overarching problem is hunger, solved in part by delivering food. In an adult literacy organization, the organization might offer classes teaching adult learners how to improve their literacy skills in particular situations. However, the problem they are trying to solve is illiteracy.

\section{Evidence that the organization is fulfilling its mission}

It is exciting to begin discussing and making plans for the organization and the problem it will address! As you continue this process, keep in mind that an essential aspect of addressing or solving a problem is knowing that you have done so, that your efforts have resulted in a measurable outcome. The only way to know this is through evaluation. Begin thinking now about what evaluation methods might be best for your particular organization. For example, in the adult literacy organization, there might be several different kinds of evaluation: client satisfaction surveys, pre-and post-literacy tests, etc. Consistent evaluation can contribute greatly to the organization's health and success.

\section{Resources}

Independent Sector. (2006). [Online] http://www.independentsector.org 